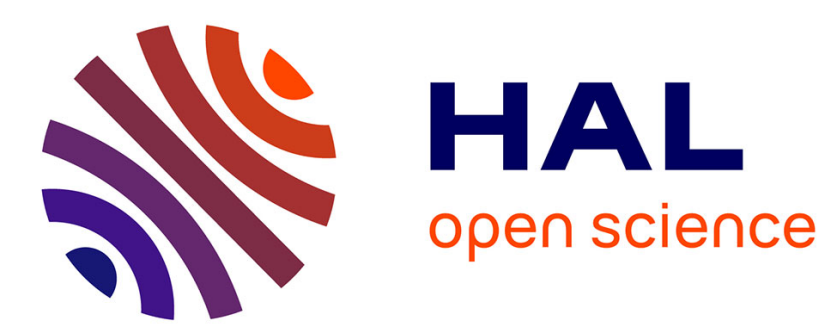

\title{
Shear Localization and Comminution of Granular and Fragmented Silicon Carbide
}

\author{
C. Shih, V. Nesterenko, M. Meyers
}

\section{To cite this version:}

C. Shih, V. Nesterenko, M. Meyers. Shear Localization and Comminution of Granular and Fragmented Silicon Carbide. Journal de Physique IV Proceedings, 1997, 07 (C3), pp.C3-577-C3-582. 10.1051/jp4:1997399 . jpa-00255556

\section{HAL Id: jpa-00255556 https://hal.science/jpa-00255556}

Submitted on 1 Jan 1997

HAL is a multi-disciplinary open access archive for the deposit and dissemination of scientific research documents, whether they are published or not. The documents may come from teaching and research institutions in France or abroad, or from public or private research centers.
L'archive ouverte pluridisciplinaire HAL, est destinée au dépôt et à la diffusion de documents scientifiques de niveau recherche, publiés ou non, émanant des établissements d'enseignement et de recherche français ou étrangers, des laboratoires publics ou privés. 


\title{
Shear Localization and Comminution of Granular and Fragmented Silicon Carbide
}

\author{
C.J. Shih, V.F. Nesterenko and M.A. Meyers \\ Institute for Mechanics and Materials, Department of Applied Mechanics and Engineering Sciences, \\ University of California, San Diego La Jolla 92093, U.S.A.
}

\begin{abstract}
Granular and pre-fractured bulk silicon carbide were subjected to high strain, high-strain-rate deformation by radial symmetric collapse of a thick-wall cylinder. Profuse shear-band formation was observed, indicating the deformation had inhomogeneous characteristics. The granular silicon carbide had lower shear-band displacement, spacing between shear bands and thickness of shear bands than the pre-fractured silicon carbide. Bimodal particle size distribution was seen inside the shear bands for both materials. The shear localization in the granular silicon carbide was primarily due to particle break-up (comminution) and rearrangement of the comminuted particles. The shear bands in the pre-fractured silicon carbide were formed through the incorporation of fragments from the shear-band interfaces and the erosion of fragments inside the shear band.
\end{abstract}

\begin{abstract}
Résumé: Des échantillons de carbure de silice pré-fragmentés et granulaires ont été soumis à des hautes déformations à hautes vitesses par l'implosion symétrique d'un cylindre à parois épaisses. La formation de bandes de cisaillement a été observée, indiquant que la déformation est inhomogéne. Le cisaillement dans les bandes la distance entre les bandes et l'épaisseur des bandes étaient plus faibles pour le carbure de silice granulé. Une distribution de taille de poudre bimodale a été observée dans les bandes pour les deux matériaux. La formation de bandes de cisaillement a été produite principalement par la fragmentation des poudres et la réorganisation des particules pulvérisées. Les bandes de cisaillement dans le matériau pré-fissuré sont formées par l'addition de fragments à partir des interfaces de la bande de cisaillement et par l'érosion des fragments à l'intérieur de la bande de cisaillement.
\end{abstract}

\section{INTRODUCTION}

The development of heavy armor that can resist modern kinetic and chemical-energy penetrators has a high technological and tactical importance. Ceramics are a critical component in modern armor systems. The recovery experiments by Shockey et al. [1] show the different regions of damage in ceramics subjected to high velocity impact. Viechnicki [2] and Meyers [3] classified the damage produced in a ceramic into (a) a comminuted zone (Mescall zone), (b) radial and conical cracks, (c) spalling, and (d) flow of the comminuted material. The flow of the comminuted ceramic proceeds in a constrained volumetric condition because the surrounding material imposes a lateral confinement. Curran et al. [4] developed a micromechanical model for the flow of this comminuted material under high-strain-rate deformation. They considered sliding and ride-up of fragments, with competition between dilatation and pore compaction. They concluded that the inelastic deformation of the comminuted material plays a key role in the resistance of ceramic to penetration. In the presence of superimposed confinement stress, the inelastic deformation of comminuted materials is not a homogeneous process. Recently, Nesterenko et al. [5] and Chen et al. [6] have demonstrated that granular and pre-fractured alumina $\left(\mathrm{Al}_{2} \mathrm{O}_{3}\right)$ exhibit profuse shear-band formation while they are subjected to large strains at high strain rates. The objective of this work is to investigate the flow of both granular and pre-fractured silicon carbide (SiC), an important structural ceramic for armor applications.

\section{EXPERIMENTAL PROCEDURES}

Silicon carbide powder, manufactured by Norton (Grade F230), was used for the granular specimens. The average particle size is about $50 \mu \mathrm{m}$, and the powder has $99.7 \%$ of purity. Commercial, hot pressed silicon 
carbide (CERCOM SiC-B) was used for the pre-fractured specimens. Quasistatic properties of the fully dense silicon carbide are listed in Table 1.

Table 1: Quasistatic Properties of Hot-Pressed Silicon Carbide (CERCOM SiC-B)

\begin{tabular}{|c|c|c|c|c|c|}
\hline Density & Grain Size & Flexural Strength & Toughness & Young's Modulus & Hardness \\
\hline $3.20 \mathrm{~g} / \mathrm{cm}^{3}$ & $4.1 \mu \mathrm{m}$ & $542 \mathrm{MPa}$ & $4.1 \mathrm{MPa} \sqrt{\mathrm{m}}$ & $450 \mathrm{GPa}$ & $23 \mathrm{GPa}$ \\
\hline
\end{tabular}

The thick-walled cylinder method was used to investigate the high-strain-rate deformation $\left(3 \times 10^{4} \mathrm{~s}^{-1}\right)$ of the granular and pre-fractured $\mathrm{SiC}$. The experimental procedures were originally developed for metals but were modified for granular and brittle materials [5-8]. This method consists of two explosive events: the first event to densify the granular $\mathrm{SiC}$ or to fracture the fully dense $\mathrm{SiC}$ and the second event to deform the ceramic.

The experimental steps are outlined in Figure 1. For the granular $\mathrm{SiC}$ specimens, $\mathrm{SiC}$ powder was loaded into a tubular cavity between a central copper rod (14.5 mm diameter) and an outer copper tube (16 mm inner diameter and $22 \mathrm{~mm}$ outer diameter). A mixture of 3:1 volume ratio of ammonite and sand was used to generate an explosion of low detonation velocity $(3.2 \mathrm{~km} / \mathrm{s})$ to densify the granular $\mathrm{SiC}$. A cylindrical orifice (11 mm diameter) was then drilled in the center of the central copper rod. The specimen then underwent a second explosive event using $100 \%$ ammonite to achieve a detonation velocity of $4.2-4.4$ $\mathrm{km} / \mathrm{s}$ to collapse the center orifice. This explosive event produced large inelastic deformation. The fully dense $\mathrm{SiC}$ specimens underwent exactly the same experimental procedures. A SiC cylinder $(16 \mathrm{~mm}$ inner diameter and $22 \mathrm{~mm}$ outer diameter) was assembled with the same central copper rod and outer copper tube. The same explosive events were conducted: the first explosive event to fracture the solid ceramic and the second explosive event to deform the fractured $\mathrm{SiC}$. The objective is to simulate the flow of the granular and fragmented ceramic under confinement. The confinement in this method is provided by the inertial compressive stresses at the boundary between the ceramic and the copper sleeve.

\section{EXPLOSIVE 1 EXPLOSIVE 2}

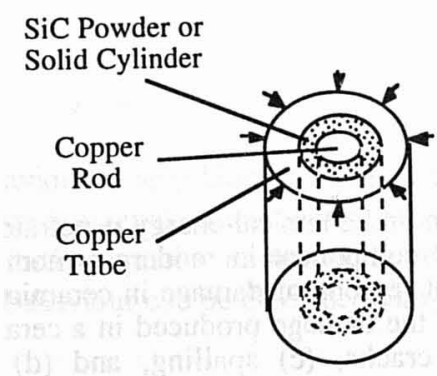

(a)

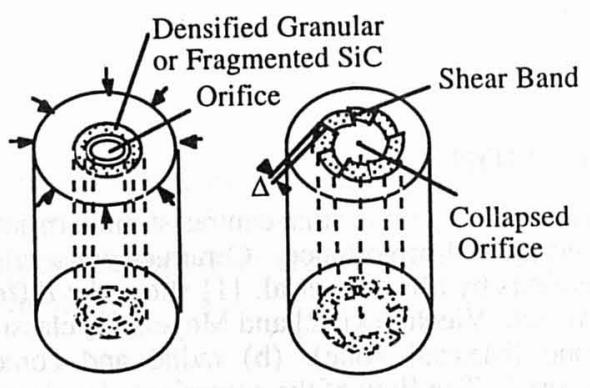

(b)

(c)

Figure 1: Experimental steps for the high-strain-rate deformation, (a) explosive event 1 to densify the granular SiC or to fracture the solid $\mathrm{SiC}$, (b) explosive event 2 for large deformation, (c) final configuration.

\section{RESULTS AND DISCUSSION}

The overview of the ceramic specimens after the second explosive event is shown in Figure 2. The global strain $\left(e_{1}\right)$, shear-band strain $\left(e_{s}\right)$ and spacing between shear bands $(L)$ can be approximated as:

$$
\mathrm{e}_{\mathrm{t}}=\frac{\mathrm{r}_{\mathrm{mf}}}{\mathrm{r}_{\mathrm{mo}}}-1 \quad \mathrm{e}_{\mathrm{s}}=-\frac{\sqrt{2} \Sigma \Delta}{4 \pi \mathrm{r}_{\mathrm{mo}}} \quad \mathrm{L}=\frac{2 \pi \mathrm{r}_{\mathrm{mf}}}{\sqrt{2} \mathrm{~N}}
$$

where $r_{m o}$ and $r_{m f}$ are the initial and final mean radii, respectively, $\Sigma \Delta$ is the summation of all shear band displacements $(\Delta$ is the shear displacement, as shown in Figure 1$)$, and $\mathrm{N}$ is the total number of shear bands. As shown in Table 2, both materials are deformed to an identical global strain $\left(e_{t} \approx-0.21\right)$, and there is a significant difference in the number of shear bands $(N)$, total shear displacement $(\Sigma \Delta)$, shear-band strain $\left(e_{s}\right)$ and spacing between shear bands $(L)$. The granular $\mathrm{SiC}$ has profuse shear bands, but its shearband displacement $(\Delta)$ is minimum. On the contrary, the pre-fractured $\mathrm{SiC}$ has a lower number of the shear bands, and the shear-band strain accounts for $58 \%$ of the global strain. 
Table 2: Macroscopic Deformation of Granular and Pre-fractured SiC

\begin{tabular}{|c|c|c|c|c|c|c|}
\hline & $\begin{array}{c}\text { Density after the } \\
\text { First Explosive }\end{array}$ & No. of bands (N) & $\begin{array}{c}\Sigma \Delta \\
\mathrm{mm}\end{array}$ & $\mathrm{e}_{\mathrm{t}}$ & $\mathrm{e}_{\mathrm{s}}$ & $\begin{array}{c}\text { Spacing (L) } \\
\mathrm{mm}\end{array}$ \\
\hline Granular SiC & $88 \%$ & 51 & $\approx 0$ & -0.205 & $\approx 0$ & 0.619 \\
Pre-fractured SiC & $99 \%$ & 16 & 10.6 & -0.228 & -0.133 & 1.907 \\
\hline
\end{tabular}

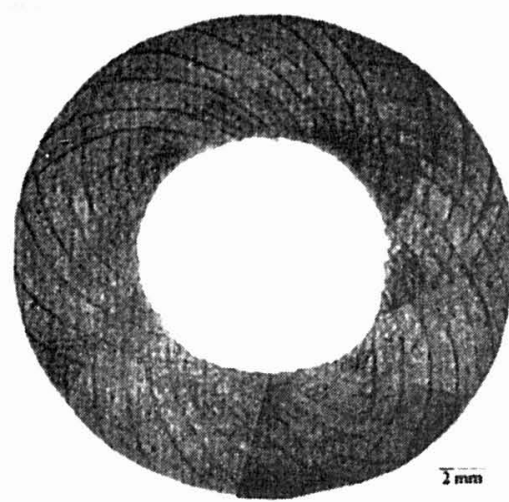

(a)

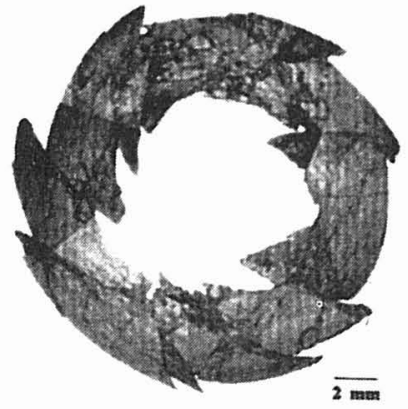

(b)

Figure 2: Ôverview of ceramic specimens after inelastic deformation to identical global strain $\left(e_{t} \approx-0.21\right)$, (a) granular $\mathrm{SiC}$, (b) pre-fractured $\mathrm{SiC}$.

\subsection{Microstructure of Shear Bands}

For granular SiC, the average thickness of the shear bands is about $20 \mu \mathrm{m}$. A bimodal particle size distribution is observed inside the shear bands, as shown in Figure 3(a). The large particles range from 10 to $30 \mu \mathrm{m}$, and the small particles are about $3 \mu \mathrm{m}$. The large particles have round corners and contain numerous microcracks. Outside the shear bands, both small and large particles can be identified. The large particle exhibit the same characteristics as the large particles inside the shear bands: round corners and microcracks. These large particles contain characteristic crack patterns, emanating from their contact points.

Similar characteristics of shear bands were observed in the pre-fractured SiC, as shown in Figure 3(b). Many shear bands exhibited two adjacent cracks. The large fragments ranged from 20 to $200 \mu \mathrm{m}$, and the small fragments were also around $3 \mu \mathrm{m}$. Round corners and microcracks were also seen in the fragments inside the shear band and in the fragments on the interfaces of the shear band. The average thickness of the shear bands is about $170 \mu \mathrm{m}$, which is a magnitude higher than the average thickness in the granular SiC.

Based on the microstructural observations, the following mechanism is proposed for shear-band formation in pre-fractured $\mathrm{SiC}$ [9]:

a. The material is first fragmented through the formation of cracks.

b. Moderate comminution proceeds through the friction of crack surfaces, corresponding to the initiation of shear bands.

c. When the two interfaces of the shear band start to move in opposite directions, the adjacent fragments are incorporated into the shear band.

d. With further shear, these fragments are rotated and eroded inside the shear band. The shear band thickens through the continuous incorporation of fragments into the band and their erosion during flow.

The mechanism for shear-band formation in granular $\mathrm{SiC}$ is similar to the pre-fractured $\mathrm{SiC}$. The major difference is related to the porosity in the granular SiC. As shown in Table 2, after the first explosive event, the densified granular $\mathrm{SiC}$ has a much higher porosity than the pre-fractured $\mathrm{SiC}$. The porosity allows the comminuted particles to rearrange themselves, without a significant volumetric dilatation. As a result, the shear-band displacement is small. The proposed mechanism for the granular SiC is as follows:

a. $\mathrm{SiC}$ powder is first compacted with moderate particle comminution. 


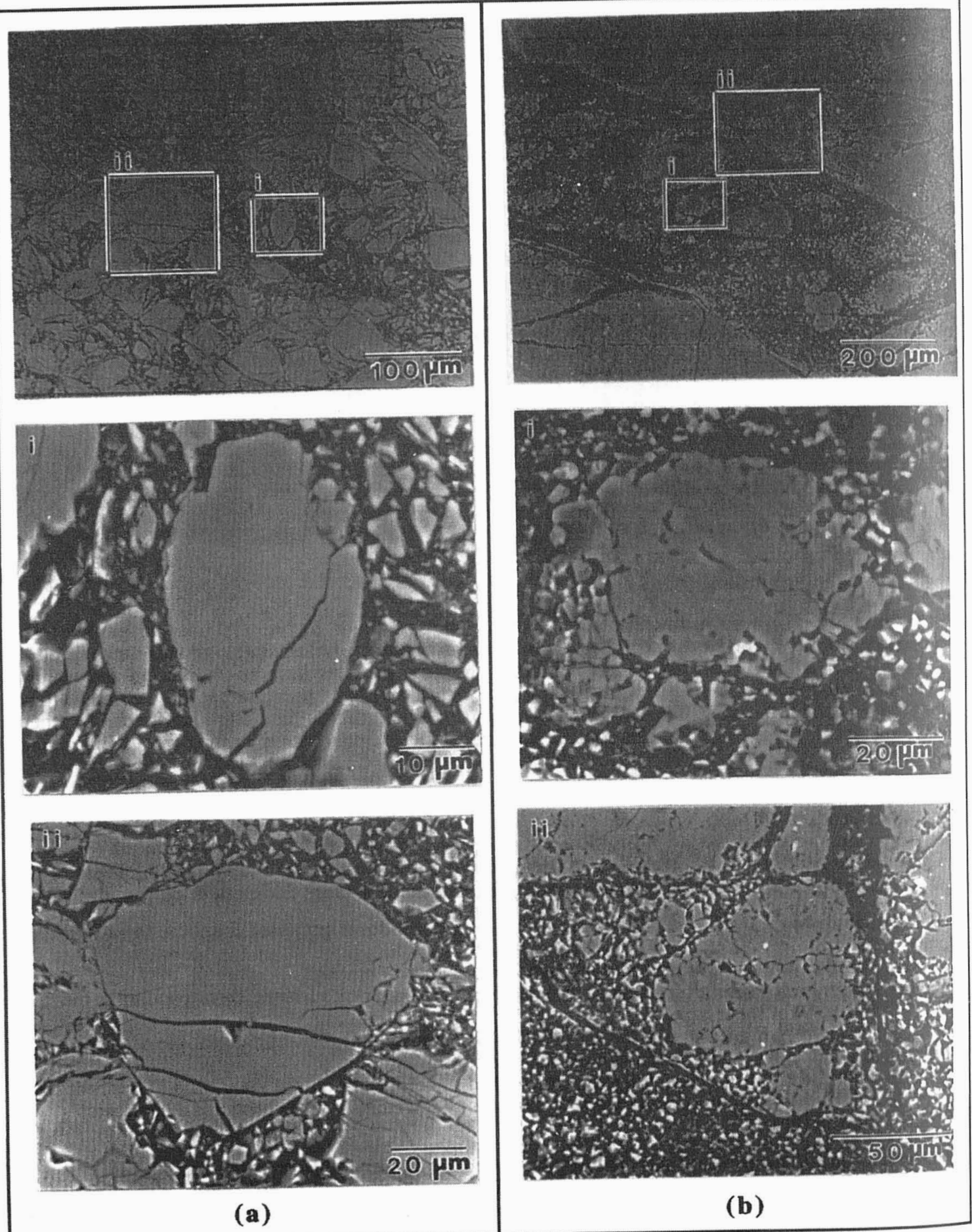

Figure 3: Microstructure of shear band, (a) granular SiC, (b) pre-fractured SiC. 
b. The compressive stress generated cracks emanating from the contact points.

c. The particles are fragmented by the coalescence of the cracks.

d. Small, comminuted particles rearrange themselves to achieve a higher packing density. Rotation and erosion of large, fractured particles occur inside the shear band during the pore compaction.

\subsection{Spacing Between Shear Bands}

The spacing between shear bands defines blocks of material that exhibit large relative translation. The treatment by Grady and Kipp [10] is based on the balance of the kinetic and strain energies of the material prior to fragmentation and the energy required to produce cracks. This analysis enables the prediction of the fragment size $(\bar{L})$ using the material resistance to crack propagation (toughness $K_{c}$ ), density $(\rho)$, sonic velocity $(\mathrm{C})$ and strain rate $(\dot{\varepsilon})$ :

$$
\overrightarrow{\mathrm{L}}=\left(\frac{\sqrt{24} \mathrm{~K}_{\mathrm{c}}}{\rho \mathrm{C} \dot{\varepsilon}}\right)^{\frac{2}{3}}
$$

This equation provides important qualitative trends, such as the effects of strain rate and resistance to shear. As shown in Table 2, the granular $\mathrm{SiC}$ has a much lower spacing between shear bands than the prefractured $\mathrm{SiC}$. The same effects were observed for prefractured and granular $\mathrm{Al}_{2} \mathrm{O}_{3}[5,6]$. The average shear-band spacing for the prefractured $\mathrm{Al}_{2} \mathrm{O}_{3}$ is $2.0 \mathrm{~mm}$, and the spacing is 0.49 and $0.61 \mathrm{~mm}$ for the granular $\mathrm{Al}_{2} \mathrm{O}_{3}$ with 0.4 and $4 \mu \mathrm{m}$ particle size, respectively. One can state that the shear-band spacing is a characteristic scale that is governed by the release of strain and kinetic energies stored in the collapsing cylinder. The granular material, with a lower resistance to shear flow has a lower shear-band spacing, in agreement with Equation (2). However, quantitative estimates are not possible because of the uncertainty in $\mathrm{K}_{\mathrm{c}}$ under compression/shear.

\subsection{Comminution}

Comminution is the size reduction process through the application of energy, usually by mechanical forces. When a sphere is crushed by a contact force $(\mathrm{F})$, a tensile stress is induced along the transverse direction of the contact force, as shown in Figure 4(a). Meyers and Meyers [11] demonstrated that the maximum tensile stress $\left(\sigma_{1}\right)$ occurs at the center of the sphere:

$$
\sigma_{\mathrm{t}}=\frac{8 \mathrm{~F}}{\pi^{2} \mathrm{D}^{2}}
$$

where $\mathrm{D}$ is the diameter of the sphere. In granular and pre-fractured ceramics, the materials can be represented by close-packed spheres, as shown in Figure 4(b). The local contact force (F) between spheres is determined by the number of contact points of the spheres, which is directly related to the sphere size (D): $\mathrm{F}=\mathrm{KPD}^{2}$, where $\mathrm{P}$ is the external pressure, and $\mathrm{K}$ is a dimensionless geometric factor. The value of $\mathrm{K}$ is in the order of one but less than unity, because not all contact forces are aligned with the external pressure. Substitute the $F$ in equation ( 3 ), one can derive:

$$
\sigma_{\mathrm{t}}=\frac{8 \mathrm{~K}}{\pi^{2}} \mathrm{P} \approx \mathrm{P}
$$

Thus, the induced tensile stress inside the spheres is independent to the sphere size. The effect of the tensile stress on an existing flaw size (2a) is: $\mathrm{K}_{\mathrm{IC}}=\sigma_{\mathrm{t}} \sqrt{ } \pi \mathrm{a}$, where $\mathrm{K}_{\mathrm{IC}}$ is the fracture toughness of the particle. Since the flaw size (2a) cannot be larger than the particle size, the following expression can be obtained, assuming $\mathrm{D}=2 \mathrm{a}$ :

$$
\mathrm{P}=\sqrt{\frac{2}{\pi}} \frac{\mathrm{K}_{\mathrm{IC}}}{\sqrt{\mathrm{D}}}
$$

Equation (4) describes the minimum pressure to comminute spheres, and is graphically expressed in Figure 4(c). A fracture toughness of $4.1 \mathrm{MPa} \sqrt{\mathrm{m}}$ (see Table 1) was assumed for the first approximation. In general, the $\mathrm{K}_{\mathrm{IC}}$ of a single-crystal ceramic is less than the $\mathrm{K}_{\mathrm{IC}}$ of a polycrystalline ceramic, because of the absence of microstructural toughening effects, such as crack deflection along the grain boundary [12]. Under a certain pressure $P^{*}$, the smallest comminuted particles would be the ones with the diameter of $D_{c}$. To further reduce the particle size through comminution, the external pressure must increase. In our highstrain-rate experiments, the magnitude of the local external pressure is not known. However, both granular and pre-fractured ceramics were deformed under identical conditions. The external pressure for these two 
types of ceramics can be considered the same. Consequently, the sizes of the comminuted particles are roughly the same $(3 \mu \mathrm{m})$ for both materials, as shown in Figure 3.

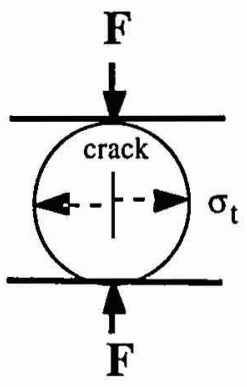

(a)

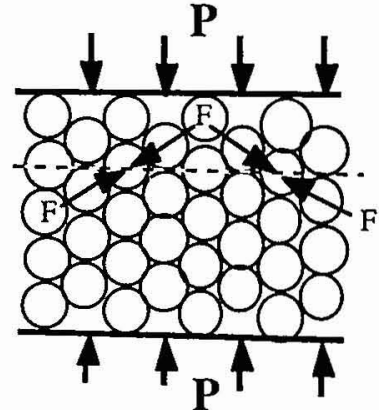

(b)

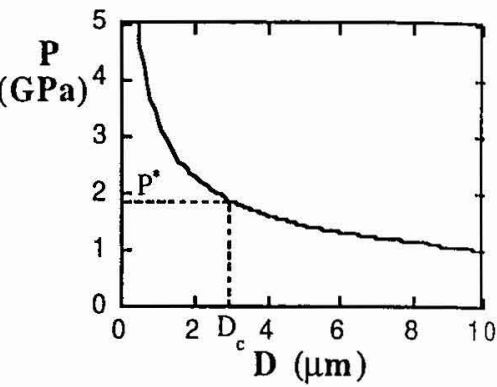

(c)

Figure 4: Particle Comminution, (a) crushing of a single particle, (b) crushing of a granular or fragmented material, (c) relationship between the external pressure and the comminuted particle size.

\section{CONCLUSION}

In large strain, high-strain-rate deformation of granular and pre-fractured silicon caroide, shear localization is an important deformation mechanism. In granular $\mathrm{SiC}$, the formation of shear bands occurs through particle comminution and rearrangement of comminuted particles. The shear bands in pre-fractured $\mathrm{SiC}$ are developed through the incorporation of fragments and the erosion of the fragments. The granular $\mathrm{SiC}$ has a higher initial porosity than the pre-fractured $\mathrm{SiC}$. During the shear-band formation, the granular SiC can be deformed through pore compaction without a significant volumetric dilatation. As a result, the granular $\mathrm{SiC}$ has a lower shear-band displacement and thickness of the shear bands. The granular SiC also has a lower resistance to shear flow and a lower resultant spacing between shear bands. Both granular and prefractured $\mathrm{SiC}$ have a bimodal particle size distribution, and the size of the comminuted particles is roughly the same $(3 \mu \mathrm{m})$. The comminuted particle size is determined by the magnitude of the external pressure. Under the same experimental conditions, both materials have the same external pressure and the same comminuted particle size.

\section{Acknowledgements}

This research is supported by the U.S. Army Research Office through AASERT (DAAH04-94-G-0314) and MURI (DAAH04-96-1-0376) programs, by the Institute for Mechanics and Materials, and by Cercom, Inc. The authors wish to acknowledge valuable help from Dr. A.A. Stertses and Mr. R.C. Dickey.

\section{References}

[1] Shockey, D., Marchand, A.H., Skaggs, S.R., Cort, G.E., Birckett, and Parker, R., Int. J. Impact Eng. 9 (1990) 263-275.

[2] Viechnicki, D.J., Slavin, M.J., and Kliman, M.I., Cer. Bull. 70 (1991) 1035-1039.

[3] Meyers, M.A., Dynamic Behavior of Materials (JohnWiley, New York, 1994) pp. 597-607.

[4] Curran, D.R., Seaman, L., Cooper, T., and Shockey, D.A., Int. J. Impact Eng. 13 (1993) 53-83.

[5] Nesterenko, V.F., Meyers, M.A., and H.C. Chen, Acta Mater. 44 (1996) 2017-2026.

[6] H.C. Chen, Meyers, M.A., and Nesterenko, V.F., "Shock Compression of Condensed Matter", APS Topical Conference, Seattle, 13-18 August, 1995 (AIP Press 1995) pp. 397-380.

[7] Nesterenko, V.F., and Bondar, M.P., Dymat J. 1 (1994) 245-250.

[8] Nesterenko, V.F., Meyers, M.A., Chen, H.C., and LaSalvia, J.C., Metall. Mater. Trans. A 26A (1995) 2511-2519.

[9] Shih, C.J., Nesterenko, V.F. and Meyers, M.A., High-Strain-Rate Deformation and Comminution of Silicon Carbide, submitted to Acta Mater., 1997.

[10] Grady, D.E. and Kipp, M.E., "High-Pressure Shock Compression of Solids", J.R. Asay and M. Shahinpoor Eds. (Springer-Verlag, New York, 1993) pp. 265-322.

[11] Meyers, M.A. and Meyers, P.P., Soc. of Mining Eng. of AIME, 274 (1984) 1875-1884.

[12] Rice, R.W., Freiman, S.W., and Mecholsky, J.J., J. Am. Ceram. Soc., 63 (1980) 129-136. 